\title{
Incontinencia Urinaria de Esfuerzo en la Mujer
}

\author{
TRATAMIENTO CON SUBSTANCIAS ESCLEROSANTES* \\ Dr. Antonio Beltrán Galindo
}

De la Cátedra de Ginecología de la Universidad de Antioquia

La incontinencia de esfuerzo en la mujer se caracteriza por la salida espontánea de orina por la uretra intacta, en circunstancias que provocan un aumento de la presión intra-abdominal, tales como toser, reir, estornudar, levantar objetos pesados, etc.

Se conoce también con el nombre de Incontinencia Ortostática o diurna.

División: Se divide en dos grandes grupos.

a) Congénita.

b) Adquirida.

La congénita es aquella que se manifiesta en la mujer desde la infancia y persiste durante toda la niñez, pubertad y edad adulta, sin que haya anomalías ni desfiguración de la estructura anatómica de los genitales ni del tracto urinario.

Adquirida: Es aquella que aparece en la mujer adulta sin previos antecedentes de incontinencia.

Se divide en tres sub-grupos:

* Presentado al IV Congreso Colombiano de Obstetricia y Ginecología. - Barranquilla, Colombia. 
$1^{\text {o }}$ Post-partum.

$2^{\circ}$ Menopáusica.

$3^{\circ}$ Post-quirúrgica.

La Post-partum, como su nombre lo indica, aparece en mujeres después o a consecuencia de un parto traumático, generalmente se atribuye al primero.

Menopáusica: Aparece en mujeres en esta época de la vida, sin previos antecedentes de ella. Según algunos autores, parece deberse a una atrofia y aflojamiento de los medios de sostén de la uretra y vejiga, ocasionados por una pérdida del influjo sanguíneo a estas estructuras, más bien, que a un efecto catabólico, ya que la administración de estrógenos, que mejoran los síntomas, obran por aumento de la vascularización en esas regiones.

Post-quirúrgico: Se presentan luego de intervenciones vaginales, generalmente colporrafias anteriores, histerectomías vaginales, operación de Manchester, y aún, se han visto en operación de Le Fort é histerectomías abdominales. Se deben a falta de conocimientos básicos de anatomía y fisiología de los cirujanos, que dejan desprovistos a la uretra, cuello vesical y vejiga, de sus soportes é inervación.

Etiología: La causa básica y fundamental es el aflojamiento de los soportes de la uretra y vejiga, que son incapaces de mantener la continencia urinaria normal.

Esta se demuestra por cisto uretrografías con medio de contraste adecuado, que pone de manifiesto lo antes mencionado, ya que se pierde la inter-relación y en el ángulo normal entre las caras posteriores de uretra y vejiga que han sido ampliamente estudiadas por Jeffcoate, Willin, Read, y otros, por Hodgkinson, etc.

Diagnóstico: Se basa en:

a) Una historia concienzudamente llevada de la paciente, recalcando en cualquier síntoma urinario que pueda orientar o descartar el síndrome.

b) Examen físico completo para percatarse del estado del 
sistema nervioso, del tono muscular, de la configuración general.

c) Examen genital minucioso que ponga de manifiesto atonías de las paredes vaginales, las fascias y los músculos que rodean vagina, uretra y vejiga.

d) Estudios radiológicos de vejiga y uretra que demuestren la pérdida de la correlación entre vejiga y vagina.

e) Examen citoquímico de orina, fácil de hacer aún en la consulta habitual para descartar infección en el tracto urinario; cistitis, uretritis, pielitis, nefritis, etc.

f) Cisto-uretroscopia para descartar las entidades antes mencionadas que pueden ser causa de error.

Diagnóstico diferencial hacerlo con:

a) Lesiones del sistema nervioso como: Vejiga neurogénica, espina bífida, tabes dorsal, parálisis general progresiva, lesiones medulares, mielitis transversa etc.

b) Infecciones del tracto Urogenital: Uretritis, cistitis, pielitis, nefritis, etc., que causan urgencia, frecuencia, poliuria y polaquiuria.

c) Anomalías congénitas del tracto urinario, como hipo y epispadias, extrofia vesical, implantación aberrante de los ureteres, etc.

d) Fistulas vésico vaginales, que se prestan a confusión; bien sean congénitas, traumáticas o post-irradiación.

e) Falsa incontinencia: Ocasionada por urgencia y frecuencia en las diversas infecciones, bien endógenas o exógenas del tracto urinario.

\section{TRATAMIENTO}

Para la corrección de la incontinencia de esfuerzo hay múltiples tratamientos; unos no operatorios, como el fisioterápico a 
base de ejercicios dinámicos o por medio del perineómetro de Kegel. El hormonal, con estrógenos, especialmente indicado en las menopáusicas; el vitamínico, por medio de la Vitamina E acompañado con faradización del cuello vesical, o el esclerosante, que es el que nos ocupa, y el quirúrgico, en el cual hay una verdadera anarquía.

Sería objeto de otro trabajo más extenso y especializado, ya que son múltiples las técnicas con modificaciones, que se emplean.

Tratamiento Esclerosante. - De relativa reciente aparición, el tratamiento esclerosante ha entrado triunfalmente y por la puerta mayor, al tratamiento de la incontinencia urinaria de esfuerzo en la mujer, con la casi unánime aceptación de todos aquellos que aún han tenido fracasos con los anteriormente mencionados.

Indicaciones. - Su uso está especialmente indicado en:

a) Incontinencia de esfuerzo congénitas puras.

b) Incontinencia de esfuerzo menopáusicas.

c) Incontinencia de esfuerzo acompañadas de ligero uretrocele.

d) Incontinencia de esfuerzo acompañadas de ligero cistocele.

Técnica. - La técnica que he empleado para su uso es la siguiente: el introito se limpia bien con algodón seco, luego se desinfecta con solución de merthiolate o similares; seguidamente se introduce una sonda de Pezzer $\mathrm{N}^{0}$ 18, que a más de evacuar la veiiga sirve, al anclar, para indicar el sitio donde se halla el cuello vesical; se aspira el contenido de la ampolla de la substancia que se va a emplear, (usamos Dondrén, de la casa Knoll, cedidos por los distribuidores en Medellín), ampolla de 1,1 c.c. a base de granugenol y substancias aromáticas disueltas en parafina.

Se deposita periorificial, alrededor del cuello vesical (Fig. 1) en tres o cuatro puntos de la hemicircunferencia inferior (Fig. 2), introduciendo una aguja delgada y larga $\left(\mathrm{N}^{0} 22\right)$ paralela al meato y a toda la uretra. No debe aplicarse en la parte superior.

Precauciones: Usar jeringa y aguja estériles. Aspirar bien con la jeringa una vez insertada la aguja para evitar caer en un 


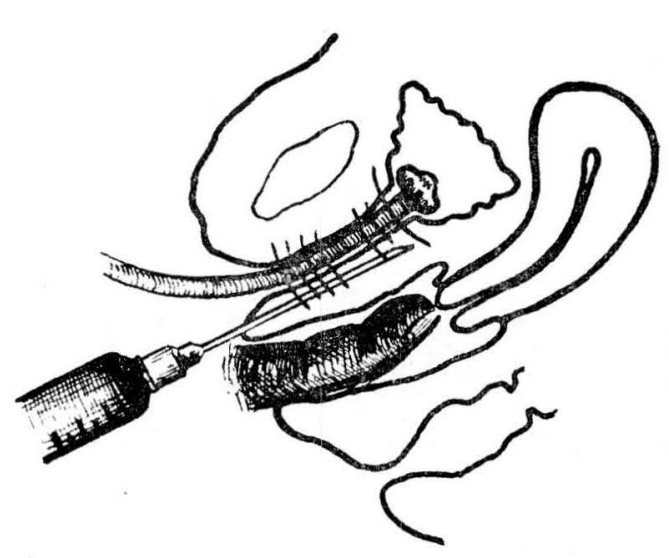

Fig. No.1

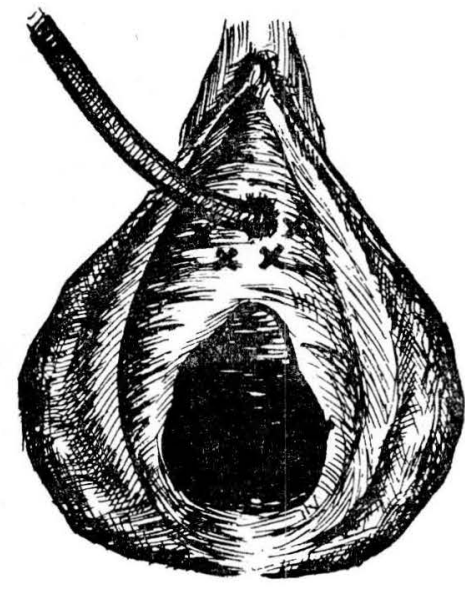

Fig. No, 2

vaso, o la de perforar la uretra y caer en la luz. No hemos tenido' ninguna de estas contingencias.

Una vez depositada la substancia se retira la aguja y la sonda de Pezzer.

Se le ordenan a la paciente reposo relativo, y si es ambulatoria, el uso de analgésicos comunes si siente dolor exagerado, y que comunique cualquier síntoma diferente a los antes presentados.

Mecanismos de acción - Esa substancia obra por esclerosis de los tejidos en su contacto, con formación de tejido fibroso que provoca un fruncimiento del esfínter interno de la uretra, lo que equivale a una de las operaciones que por vía vaginal se emplean también con este fin.

\section{RESULTADOS}

El número de incontinentes tratadas fué de 16, de las cuales 5 pertenecen al I.C.S.S., seccional de Antioquia, y las restantes al servicio de la Clínica Ginecológica del Hospital de San Vicente de Paúl de Medellín. 
De las 16 tratadas por este método quedaron totalmente curadas 11 , o sea el $68,75 \%$; mejoraron de su sintomatología 2 , o sea el $12,5 \%$ y no respondieron al tratamiento o se perdieron de control 3 , o sea el $18,75 \%$.

En ese grupo total, 5 habían sido sometidas a previa intervención, de las cuales a 2 de ellas se les hizo una operación de Marshall-Marchetti para corregir su incontinencia de esfuerzo; a 2 colporrafia anterior para corregir cistocele y en 1 cierre de fístula vésico-vaginal post-partum.

Hubo una paciente con incontinencia de esfuerzo congénita, que respondió exitosamente al tratamiento y pudo posteriormente casarse.

Complicaciones. - En la mayoría se presentó dolor exagerado en el sitio de depósito de la substancia, el cual respondió a

los analgésicos comunes. La casa productora cree de buen pronóstico este síntoma. En una se formó un pequeño absceso, el cual fué drenado, sin mayores complicaciones, teniendo a mano los antibióticos comunes.

\section{CONCLUSIONES}

1 - Es un método sencillo y poco cruento.

2 - Lo fácil de practicar y la poca exigencia de instrumental.

3 - Lo eficaz y benigno del producto.

4 - Su uso en pacientes vírgenes que toleran el tacto unidigital, o la dilatación himeneal con Kinadena.

5 - Su empleo en pacientes que han sido infructuosamente operadas, y en donde la cicatriz dificultaría la reintervención.

6 - Las pacientes pueden ser tratadas ambulatoriamente. 